\title{
Redemoinhos da AtLANTida (1915-1920)
}

\author{
Lucia Maria Paschoal Guimarães* \\ luciamp@uol.com.br
}

Resumo: O artigo examina o papel desempenhado pela revista Atlantida, o mais expressivo veículo de divulgação de um projeto político-cultural, voltado para a defesa da formação de uma comunidade luso-brasileira. Dirigido no Rio de Janeiro por Paulo Barreto, o popular João do Rio, e em Lisboa por João de Barros, o periódico circulou mensalmente entre 1915 e 1920. Constituiu um espaço de fermentação intelectual e de sociabilidade. Ao lado da permanente reflexão doutrinária acerca da conveniência do estreitamento das relações entre Brasil e Portugal, a revista ocupava-se de questões literárias, históricas e artísticas contemporâneas, o que lhe conferia um alcance político e ao mesmo tempo cultural.

Palavras-Chave: Atlantida, revista cultural, comunidade luso-brasileira, João de Barros, João do Rio, relações luso-brasileiras.

Redemoinhos DA ATLANTIDA

Em 15 de novembro de 1915, o lançamento de uma nova revista agitou o mundo letrado luso-brasileiro. Tratava-se da Atlantida. Mensário Artístico, Literário e Social para Portugal e Brasil, dirigida a quatro mãos, pelo carioca João do Rio e o português João de Barros. O batismo literário teve lugar na cidade de Lisboa, e a data que pretendia homenagear a passagem do vigésimo sexto aniversário da proclamação da República no Brasil.

* Professora Titular da Universidade do Estado do Rio de Janeiro. Este artigo apresenta resultados parciais da pesquisa "Atlantida (1915-1920): A luso-brasilidade em revista", apoiada pelo CNPq, bem como pelos Programas Prociência, da Universidade do Estado do Rio de Janeiro (UERJ) e "Cientista do Nosso Estado" da Fundação Carlos Chagas de Amparo à Pesquisa do Estado do Rio de Janeiro (FAPERJ). 
O nome da publicação fora escolhido por João do Rio, que se inspirou na lenda do continente perdido, para designar de forma semântica um projeto que buscava (re) estabelecer a ligação entre as duas partes do mundo que as águas do oceano haviam separado ${ }^{1}$. O subtítulo, Mensário Artístico, Literário e Social para Portugal e Brasil, além de indicativo da periodicidade, resumia o seu teor programático e destacava-lhe o caráter binacional.

Na página seguinte à folha de rosto, em posição de destaque, exibia-se a informação de que o periódico recebia o [...] alto patrocínio de $S$. Ex. ${ }^{\text {as }}$ os ministros das Relações Exteriores do Brasil e dos Estrangeiros e do Fomento de Portugal, acompanhada dos votos de congratulações, formulados por aquelas autoridades, respectivamente, os doutores Lauro Muller, Augusto Soares e Manuel Monteiro. Este último reportava-se ao empreendimento como [...] um esteio seguro da indispensável aproximação intelectual e econômica entre as duas Pátrias irmãs. Aliás, as três mensagens são pistas de um possível envolvimento dos dois governos na iniciativa editorial.

A conveniência da aproximação entre os dois países começou a ser aventada por Silvio Romero (1851- 1914), na conferência "O elemento português no Brasil: a imigração e o futuro do povo brasileiro", pronunciada em 1890, no Gabinete Português de Leitura do Rio de Janeiro, e publicada em Lisboa sob a forma de panfleto, em 1902. Cabe acentuar que alguns anos antes o escritor e crítico literário, na primeira edição da sua História da Literatura Brasileira, mostrara-se um censor implacável da matriz cultural lusíada (ROMERO, 1888). No entanto, mudou opinião. Passou a defendê-la com vigor, diante de uma possível ameaça do imperialismo alemão, externada em jornais europeus, como ele próprio indicava:

[...] Os pangermanistas estão atualmente ocupados com um projeto de organização mais sólida de um acordo entre os colonos alemães no Brasil. Tem havido em diversas cidades da Alemanha conferências cujo fim é enviar alguns pastores, padres e mestres-escola ao sul do Brasil. Na cidade de Magdeburgo um dos oradores declarou que parte do sul do Brasil é terra alemã e que deverá mais tarde pertencer ao império germânico (ROMERO, 1902, p. 35).

Silvio Romero justificava suas preocupações, argumentando que nos estados meridionais do Brasil existia forte concentração de emigrantes de origem germânica, reunidos em comunidades, onde [...] a língua portuguesa brilha pela ausência. Alarmado, advertia que [...] a língua, por si só, na era presente serve para individualizar a nacionalidade, é por isso 
que os alemães consideram a pátria alemã todo e qualquer sítio onde é falada a língua alemã. Antevia que por volta de oitenta ou cem anos, no mais tardar, [...] o núcleo do Rio Grande do Sul, ao que parece o mais populoso e compacto, tornar-se-á independente e, estendendo a mão ao de Santa Catarina, aliar-se-á com ele, formando ambos a nova nacionalidade (ROMERO, 1902, p. 35).

A integridade da Terra de Santa Cruz parecia estar em risco e Romero apregoava a necessidade de fortalecer os elementos que historicamente a constituíam como nação luso-brasileira, em especial, o idioma. Contudo, nas suas reflexões, ele iria ainda mais longe sinalizando que a ambição alemã não se limitava ao território brasileiro: [...] Portugal também faz parte das nações pequenas, mas também pertence ao grupo dos ameaçados, quando não diretamente nas suas plagas européias, de modo inequívoco na África (ROMERO, 1902, p. 42) Para enfrentar o perigo comum, o escritor sugeria que Brasil e Portugal se unissem e formassem uma federação.

As inquietações que afligiam o letrado brasileiro, por certo, também afetavam a intelectualidade lusa. Mas, a ideia de celebrar uma aliança com a antiga colônia americana só viria a ser expressa, publicamente, por Coelho de Carvalho, na Academia das Ciências de Lisboa, em 1909. Pela mesma ocasião, a Sociedade de Geografia decidiu abrir um concurso de monografias sobre "o modo mais eficaz de promover a união moral dos portugueses residentes no Brasil com a mãe pátria" e anunciou a intenção de organizar uma expedição de estudos ao interior do país. Logo em seguida, o presidente da Sociedade, deputado Zófimo Consiglieri Pedroso, propôs a consecução de um plano que ficou conhecido por Acordo Luso-Brasileiro, sugerindo a instituição de um grupo de trabalho permanente, encarregado de estudar medidas para a consecução dos seguintes objetivos: negociar tratados de arbitragem, de cooperação internacional e de comércio; ensejar a criação de entrepostos comerciais e a construção de palácios de exposição em Lisboa e no Rio de Janeiro; promover na medida do possível a unificação da legislação civil e comercial; encorajar a cooperação intelectual - científica literária e artística - conferindo equivalência de direitos ou de títulos aos diplomados de um país que decidissem trabalhar no outro; planejar visitas recíprocas de intelectuais, artistas, industriais e comerciantes, bem como fomentar a convocação de congressos científicos e a colaboração entre jornalistas, editores, associações culturais, pedagógicas, artísticas e beneficentes (RIO, 1911, p. 289-292).

O ambicioso programa permaneceria no terreno das intenções, pois seu autor faleceu pouco tempo depois de expô-lo. A par disso, havia poucas 
chances de levar avante tal projeto, considerando a atmosfera de instabilidade política, que marcou o fim da monarquia e o advento da República portuguesa, em 1910.

As ideias de Consiglieri Pedroso, no entanto, voltariam a ser ventiladas com a deflagração da Primeira Grande Guerra. No parlamento português, vozes nacionalistas manifestavam seus receios diante do avanço alemão. O deputado João Menezes, por exemplo, assinalava que [...] brasileiros $e$ portugueses têm de pensar, hoje mais do que nunca, em estreitar suas relações políticas, podendo ir muito além duma aliança (SIMÕES, 1960, p. 34).

No Brasil, o contexto da guerra também favoreceria a disseminação de culturas políticas de cariz nacionalista. No entanto, as opiniões se dividiam no que se refere à aproximação entre os dois países. Havia quem repudiasse a ideia de uma aliança com Portugal. Herdeiros da vertente mais radical do nacionalismo, admiradores do presidente Floriano Peixoto, que rompera relações diplomáticas com Portugal em $1894^{2}$, responsabilizavam a colonização lusa pelo atraso cultural, econômico e social do país. Nessa corrente, entre outros vultos, sobressaíam-se o médico e pedagogo Manoel Bonfim, além dos escritores Antonio Torres, Felix Amélio, Jackson de Figueiredo e Álvaro Bomilcar, que disseminavam o anti-lusitanismo em publicações, como O Tempo, Brazilea e Gil Blas, além de incitar a população a participar de campanhas anti-portuguesas (ALVES, 2005, p. 223).

Os partidários do congraçamento cultural e político com a antiga metrópole, por seu turno, tal qual Silvio Romero, percebiam no legado lusíada o fator dominante da construção da nacionalidade, baseados na afinidade lingüística, no passado histórico e na ocupação do território. A tese desfrutava da acolhida não apenas de destacados membros da colônia portuguesa no Rio de Janeiro, como também de intelectuais da envergadura de Olavo Bilac, de Afrânio Peixoto, de Paulo Barreto e de Graça Aranha, membros atuantes da Academia Brasileira de Letras (RODRIGUES, 1923, p. 8). Já o nome de Paulo Barreto (1881-1921), ou melhor, o seu pseudônimo literário mais famoso, João do Rio, acabaria ligado a um dos esforços mais significativos para estimular o aprofundamento dos laços entre os dois países: a criação da já mencionada revista Atlantida, fruto da sua associação com o poeta, publicista, político e pedagogo português João de Barros (1881-1960), "um incansável apóstolo da aproximação luso-brasileira, como cidadão e governante, como conferencista e escritor" (SARAIVA, 2004, p. 81-2).

João de Barros e João do Rio se avistaram pela primeira vez, em 1908, durante uma das visitas do escritor carioca a Portugal. O encontro ocorreu na cidade do Porto, na livraria dos irmãos Lello, promovido por 
um amigo comum, Manoel de Sousa Pinto, e marcou o início de um sólido relacionamento pessoal e profissional. Anos mais tarde, João do Rio relembraria o episódio, salientando que durante a conversa descobriram fortes afinidades, a começar pelas ideias políticas, pois ambos professavam o ideário republicano. Além disso, preocupavam-se com o futuro incerto das relações luso-brasileiras, porquanto [...] se o Brasil se interessava menos por Portugal do que pela França, Portugal não se interessava, ou antes, ignorava tudo do Brasil ${ }^{3}$.

A solução do impasse, por certo, demandava ações oficiais mútuas, contudo, os dois letrados poderiam somar esforços, quem sabe, criando uma revista literária binacional, de modo a estimular o sentimento de lusobrasilidade. O plano ganharia fôlego com a vinda de João de Barros ao Brasil, em 1912. Ele passou a postular o fortalecimento dos vínculos entre Brasil e Portugal, baseando-se não apenas nas simpatias espirituais das tradições do passado, mas também pela conveniência do futuro (BARROS, 1919, p. 7). A este argumento de João de Barros cabe complementar com outro de João do Rio, o de que [...] a guerra veio definitivamente forçar a publicação ${ }^{4}$.

Com efeito. No número de lançamento da Atlântida, sob a forma

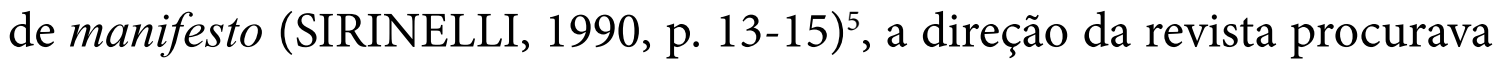
justificar o empreendimento e explicitar a sua linha programática:

[...] Há muito tempo que a publicação d'uma revista literária que defendesse os interesses comuns do Brasil e de Portugal se impunha e se tornava indispensável. [...] As características especialíssimas criadas pela Guerra européia determinaram um irresistível movimento de solidariedade entre aqueles países e aqueles povos que vivem d'um mesmo ideal, que se alimentam da mesma tradição ou que descendem do mesmo tronco originário. [...]. Acontece, porém, que não se conhecem. [...] É precisamente para que Portugal conheça o Brasil e que o Brasil mais se aproxime de Portugal e melhor se conheça, que se vai publicar a Atlantida. [...] É uma obra patriótica esta nossa. E ensinando as duas democracias que o Oceano Atlântico separa, a melhor amar-se e compreender-se a Atlantida tentará substituir, 'no domínio intelectual e social' aquele lendário continente que dantes ligou a América à Europa... ${ }^{6}$ (grifo nosso).

O texto oferece algumas pistas que vale a pena explorar. Sobretudo, no que diz respeito à associação entre a guerra e o lançamento de uma revista, que se afirmava voltada apenas para os domínios intelectual e social. João 
de Barros apontaria um indício da conexão, em uma conferência proferida no Ateneu Comercial do Porto, em 1919, reportando-se às pretensões alemãs na América do Sul (BARROS, 1919, p. 16-17). Referiu-se à existência de um programa de emigração direcionado para a conquista do Brasil, preparado por um certo Sr. Lange, e ao projeto do pensador Otto Richard Tannenberg, sintetizado no livro A Grande Alemanha: a obra do século $X X$ (TANNENBERG, 1916). Aos comentários de João de Barros, não seria demais acrescentar, havia também o problema da preservação do império colonial português, alvo da cobiça anglo-germânica, e de sucessivas incursões do exército do kaiser Guilherme II em Angola e Moçambique.

A Atlantida era publicada em Lisboa. Seu escritório, comandado por João de Barros, localizava-se no Largo do Conde Barão. A redação sob a responsabilidade de Pedro Bordallo Pinheiro estava sediada na rua Barata Salgueiro. Nos créditos da revista não consta a existência de um corpo editorial permanente, nem a indicação da quantidade de exemplares que circulava a cada tiragem. Em Portugal, a assinatura anual custava $2 \$ 80$, a semestral $1 \$ 50$, enquanto o número avulso podia ser adquirido por $\$ 25$. Já no Brasil, vendiam-se apenas assinaturas anuais por $12 \$ 50$ e semestrais por $7 \$ 00$, quantias razoavelmente acessíveis para a época, considerando o bom padrão gráfico da publicação.

A revista possuía editoração de qualidade. De formato sóbrio, impressa em papel mate, alguns textos eram ilustrados com desenhos e fotografias, outros decorados com caprichadas vinhetas artísticas. A disposição das matérias respeitava certa ordem, de maneira a formar dois conjuntos distintos, cujo número de páginas podia variar bastante. O primeiro bloco agregava contribuições literárias, artigos, ensaios e biografias, bem como reproduções de telas de pintores famosos e de obras de arte. O segundo compunha-se de três seções fixas, a saber: "Revista do Mês" - uma síntese dos principais fatos culturais e políticos ocorridos no período; "Livros" - espaço destinado à divulgação do lançamento de publicações e às resenhas críticas; "Notícias e Comentários" - segmento reservado às cartas de leitores e observações do gênero. Aceitava-se publicidade paga, em geral, reclames de empresas, escritórios, lojas, bancos e companhias de seguro, porém, não há qualquer menção de valores cobrados a anunciantes.

A princípio, o conteúdo do mensário privilegiava majoritariamente o domínio das letras - poesia e prosa. Os colaboradores não percebiam remuneração e, no que diz respeito à nacionalidade, observa-se a preeminência de autores portugueses. Esta constatação, todavia, não pode ser tomada como sinal de desprestígio do periódico, apesar da sua proposta não contar com 
o apoio unânime da intelectualidade brasileira, conforme já se sublinhou. O predomínio dos conterrâneos de Camões, em larga medida, deve ser atribuído ao estado de guerra, que tornava bem mais difícil a comunicação e o transporte regular entre o Rio de Janeiro e Lisboa ${ }^{7}$.

Um rápido inventário das matérias publicadas revela a presença de poemas de Olavo Bilac, de Antonio Correia d'Oliveira, de Júlio Dantas, de Augusto Gil, de Oscar Lopes, de João de Barros e de Mário de Alencar; contos de Afrânio Peixoto, de Júlia Lopes de Almeida, de Teixeira de Queiroz, de Manoel de Sousa Pinto; crônicas de Aquilino Ribeiro, de João do Rio, de Aurélio da Costa Ferreira, de João Luso e de Humberto d'Avelar. Nomes de sólida reputação na esfera literária luso-brasileira, conquanto representassem correntes estéticas e teóricas diversas. Aliás, a mélange talvez possa explicar porque os especialistas de história da literatura, apesar de fazerem reiteradas referências à revista e a seus diretores, não aprofundam a análise do seu conteúdo (CONCEIÇÃO, 1997).

De qualquer modo, o ecletismo aqui indicado parece confirmar o propósito anunciado por João de Barros de acolher figuras de todos os quadrantes do mundo letrado, "sem virar a casaca", isto é, sem abrir mão do ideário republicano, professado por ele e por João do Rio. A mistura de tendências, no fundo, constituía uma estratégia calculada. Buscava-se, assim, atrair novos simpatizantes para a causa da revista e conquistar um público leitor mais numeroso.

Prática semelhante pode ser observada na mescla dos autores de artigos, ensaios e biografias. O leque compreendia desde políticos da envergadura do positivista Teófilo Braga, do ministro Manuel Monteiro e dos presidentes Bernardino Machado e Afonso Pena, até diplomatas como Hélio Lobo, Araújo Jorge, Domício da Gama, Fran Paxeco, Veloso Rebelo e Alberto d'Oliveira, passando por figuras conhecidas do panorama cultural luso-brasileiro, a exemplo do arquiteto Raul Lino, de Luís da Câmara Reys, de Bento Carqueja, Carlos Malheiro Dias, de Raul Pederneira, de João de Deus Ramos, de Leão Veloso Neto, de Celso Vieira, de Moreira Teles, de Aureliano Leal e de Victor Vianna, entre outros.

A intensificação da guerra, como já se poderia prever, acabou por reforçar o caráter doutrinário do Mensário. A militância cultural em prol da aproximação dos "povos irmãos" desaguou na proposição de uma "íntima aliança política" entre as duas nações. E, sem dúvida, a ameaça do avanço do pangermanismo foi um dos fatores que mais contribuiu para impulsionar tal projeto. Neste sentido, em 1917, a Atlantida divulgou uma entrevista concedida a João de Barros pelo representante português na França, o dr. 
Antonio Maria de Bettencourt Rodrigues ${ }^{8}$, com um sugestivo título "Uma ideia a defender - A Confederação Luso-Brasileira”, acrescido da pergunta "Será possível uma nova e grande Lusitânia?".

O embaixador sugeria a união Portugal-Brasil, reportando-se a outro colega de ofício, D. Luís da Cunha, que aconselhara ao rei D. João V transferir a corte portuguesa para o Rio de Janeiro. Rememorou, ainda, as ideias de Silvio Romero, de Coelho de Carvalho e o "acordo" formulado por Consiglieri Pedroso, apontando a sua conveniência, à luz do contexto internacional contemporâneo. Entretanto, fazia uma advertência:

[...] um simples acordo ou aliança tem deixado o Brasil um pouco indiferente. [...]É vermos o sucedido às várias tentativas para um tratado de comércio e às projetadas linhas de navegação [...]. A ideia de uma confederação, essa sim, não poderá deixar de impor-se à atenção dos brasileiros e portugueses, 'mormente nesta ocasião em que se jogam nos campos de batalha os destinos das nações, ou, para melhor dizermos, das diferentes raças que procuram alicerçar em novas bases os seus respectivos agrupamentos [...]' (grifo nosso) ${ }^{9}$.

No entender de Bettencourt Rodrigues, a junção dos dois países, sob a forma federativa, apresentava vantagens inquestionáveis, tanto de natureza geopolítica, quanto no âmbito econômico. Suas reflexões, ao que tudo indica, inspiravam-se nas denúncias contra o programa imperialista alemão, perpetradas em 1916, pelo jornalista e geopolítico francês André Chéradame livro Le plan pangermaniste démasqué (CHÉRADAME, 1916). Sabe-se que esta obra causara forte impacto no mundo Atlântico. Basta dizer que a versão em inglês, lançada nos Estados Unidos, alcançou duas edições em menos de seis meses, conforme se lê na resenha do The New York Times, de 27 de julho 1917. Por essa mesma ocasião, no Rio de Janeiro, a Livraria Garnier publicou uma tradução em língua portuguesa, com o título "O plano pangermanista desmascarado", acrescida de um prefácio preparado por Graça Aranha (1868-1931), intitulado "Brasil e pangermanismo" (GRAÇA ARANHA, 1917).

Tal como André Chéradame, Bettencourt Rodrigues apontava para a ameaça da dominação germânica no Atlântico Sul, valendo-se de argumentos bem pragmáticos:

[...] Basta olhar um mapa para que delas nos certifiquemos. De um lado e de outro do Atlântico o que vemos? Numa extensíssima margem da América Austral, o Brasil; quase em frente, na costa africana, a vasta colônia de Angola; e, entre elas, como um mar lusitano, o Atlântico sul. Numa zona de 
navegação comum ao Brasil e à África ocidental - o arquipélago de Cabo Verde. E mais ao norte, como pontos de escala em rotas diferentes - os Açores e a Madeira. E, no ponto de convergência de inúmeras linhas de navegação, como vasto entreposto comercial dos produtos de Portugal e Brasil - o amplo e magnífico porto de Lisboa....

Segundo o diplomata luso, o sistema internacional atravessava uma fase de transformação, fruto da combinação de diversos fatores, a começar pela expansão colonial da Inglaterra e da França, o despertar do Japão para a civilização moderna e o seu latente imperialismo, e a hegemonia que os Estados Unidos se propunham a exercer sobre o continente americano. Outro aspecto a ser considerado era propagação de movimentos políticos como o pan-germanismo, o pan-eslavismo e o pan-iberismo. A nova ordem internacional, de acordo com suas projeções, deveria caracterizar-se pela formação de [...] grandes agrupamentos de povos, estados e nacionalidades, sob uma só bandeira, e tendo como base, ou o território, ou a raça, ou interesses de ordem econômica [...]. Ao fim e ao cabo, Bettencourt Rodrigues lançaria uma questão instigante:

[...] porque se não há de também, e com melhores razões, levantar, em Portugal e no Brasil, o problema do lusitanismo? Que outro agrupamento étnico apresenta [...] uma maior unidade de pensar e sentir, mais íntimas afinidades de ordem afetiva e de mais ajustáveis superfícies de coesão? Ligados no passado por glórias e tradições comuns, porque não hão de portugueses e brasileiros, unindo seus destinos, constituir uma nova e grande Lusitânia? ${ }^{10}$

Concluindo a entrevista, o embaixador revelou a intenção de escrever a alguns homens ilustres do Brasil, com o intuito de sondar a repercussão da sua proposta. João de Barros, por sua vez, comprometeu-se a divulgar tais manifestações nas páginas da Atlantida, bem como de ouvir algumas individualidades portuguesas a esse respeito.

De fato. Sob a denominação "O inquérito da Atlantida - Confederação Luso-Brasileira”, a revista abriu espaço para uma nova seção, destinada a publicar as opiniões emitidas. O primeiro pronunciamento veio da parte do capitão de mar e guerra Henrique Lopes de Mendonça, personalidade que desfrutava de grande prestígio tanto nas classes armadas, quanto nos meios intelectuais de Portugal ${ }^{11}$. O comandante não apenas aplaudiu como reforçou a proposta, tecendo conjecturas sobre a formação de novos alinhamentos geopolíticos no Atlântico. Presumia que no hemisfério norte a coligação integraria a Inglaterra e Estados 
Unidos, enquanto que no sul deveria reunir Portugal e Brasil. Para Lopes de Mendonça, a consecução do projeto viria efetivar [...] um belo sonho: $o$ do pan-lusitanismo [...], .o engrandecimento da pátria comum ${ }^{12}$.

Outro oficial da Marinha portuguesa, o tenente Nunes Ribeiro ${ }^{13}$, salientou a pertinência do plano em seus aspectos militares e econômicos. Assegurava que [...] a garantia do domínio do mar no Atlântico Sul é e será sempre um objetivo comum aos dois países. Aconselhava, inclusive, que cessado o estado de guerra, Brasil e Portugal fossem unidos à Conferência da Paz [...] com seus interesses perfeitamente ajustados e definidos ${ }^{14}$.

Curiosamente, da banda ocidental do Mar-Oceano, a exceção das já esperadas declarações de apoio de João do Rio, a publicação divulgou a opinião de apenas um brasileiro, o jurista Arthur Pinto da Rocha. Ouvido por João de Barros em Lisboa, ele ponderou que não existiam maiores obstáculos de natureza jurídica que pudessem inviabilizar o estabelecimento da "confederação". Destacava que no Brasil, [...] o direito civil foi por muito tempo as Ordenações, [...] o Código Comercial vigente é inspirado no Código Português de 1833. A atual Constituição Portuguesa, em mais de uma disposição, nada mais é do que uma [...] reprodução exata da nossa Carta de 24 de fevereiro, assim por diante $[. . .]^{15}$.

O "Inquérito" teve continuidade, com outras manifestações favoráveis. Entretanto, os ventos da falta de recursos e da instabilidade política em Portugal, com o advento da ditadura de Sidonio Pais ${ }^{16}$, envolveram a Atlantida num redemoinho. A periodicidade da revista tornou-se irregular e sua circulação chegou a ser suspensa durante alguns meses, em 1918.

A revista sobreviveu às intempéries e reapareceu, em 1919. Mas, tudo leva a crer que, cessado o perigo alemão, seus fundadores tencionavam alterar-lhe o foco e alcançar também as ondas do Mediterrâneo, ainda que se mantivessem firmes no propósito de defender o estabelecimento de uma comunidade luso-brasileira. A partir do $\mathrm{n}^{\circ} 37$, que corresponde provavelmente ao mês de abril daquele ano, deixou de ostentar o subtítulo "Mensário artístico, literário e social para Portugal e Brasil”, para converter-se em "Órgão do pensamento latino no Brasil e em Portugal”. Além disso, passou a ser gerida por um colegiado formado por quatro diretores: dois portugueses, João de Barros e Nuno Simões, e dois brasileiros, João do Rio e Graça Aranha, este último sediado em Paris. Em uma nota aos leitores, justificavam-se as mudanças e ressaltava-se que a nova composição da diretoria simbolizava (...) a garantia segura da atitude que esta revista tomará sempre nas questões e problemas que interessam a vitória do espírito latino nos dois países atlânticos, e o triunfo da intima união entre Portugal e Brasil ${ }^{17}$. 
Com o fim da guerra, a corrente da Atlantida parecia haver recobrado o vigor. Naquele mesmo número, em seu primeiro pronunciamento publicado, o novo diretor Graça Aranha reafirmava as finalidades do projeto da revista e sublinhava que:

[...] O mesmo caráter de raça anima os dois povos, a mesma lei de vida funde espiritualmente os dois países. A união política entre Portugal e Brasil, conseqüência da unidade moral das duas raças, seria a grande expressão internacional da raça portuguesa. [...] Para se justificar esta magnífica aspiração das duas nações e da mesma língua bastaria o sentimento da defesa do patrimônio português ameaçado há pouco pela cobiça da Alemanha ${ }^{18}$.

Batendo na mesma tecla, João de Barros, em um artigo acalorado, levantava uma indagação crucial: [...] A vitória dos aliados trouxe consigo, a vitória dos grupos étnicos. Será agora a ocasião de fazer triunfar - no Brasil e em Portugal - o nosso lusitanismo comum? [...] Será ou não será agora a ocasião de alicerçar em bases indestrutíveis, não direi diplomáticas, mas de interesses comuns, que aos dois países convém?

A maré da Atlantida parecia subir novamente. Em suas páginas, anunciava-se com entusiasmo a inauguração da cadeira de Estudos Brasileiros, na Universidade de Lisboa, cujo primeiro curso deveria ser ministrado por Miguel Calmon, indicado pela Academia Brasileira de Letras. Do mesmo modo, festejou-se a presença em Portugal de Epitácio Pessoa, naquela altura chefe da delegação brasileira à Conferência da Paz, em Paris, e recém eleito presidente da república. Por sinal, essa visita deu-se graças ao empenho dos dois Joões, que também se encontravam na capital francesa, acompanhando os trabalhos da Conferência. Segundo o relato deixado por João de Barros, Epitácio estaria pouco disposto a realizá-la:

[...] porque receia ou supõe, acentuou João do Rio, que a desordem lavre ali. No momento em que o São Paulo (encouraçado) que o trazia, passou em Lisboa, rebentavam as granadas e os tiros deflagravam a cada momento. Fora nos momentos de luta em Monsanto. É necessário convence- lo a ir a Portugal, para dessa maneira dar ao mundo a certeza da fraternidade luso-brasileira. Mal nos iria se o São Pulo não tocasse em Lisboa. Vê se convences o Epitácio.

Durante uma festa na representação brasileira em Paris, João de Barros executou a trama engendrada por João do Rio. Muito sutilmente, aproximou- 
se de Epitácio Pessoa, garantiu-lhe que a situação política em Portugal voltara à normalidade e o consultou sobre a possibilidade de realizar uma rápida visita a Lisboa, na viagem de regresso ao Rio de Janeiro. O presidente não lhe respondeu, mas também não reagiu negativamente à sondagem. Diante disso, João de Barros correu para a Legação lusíada e relatou a conversa com Epitácio aos seus conterrâneos, que decidiram levar adiante o plano adiante e oferecer-lhe um banquete para formalizar o convite, afinal aceito.

O futuro chefe de estado brasileiro, além de acolhido com as formalidades protocolares, seria homenageado no parlamento português por outro diretor da Atlantida, o deputado Nuno Simões, que aproveitou a oportunidade para enfatizar a importância das propostas que a publicação vinha defendendo:

[...] Feliz e gloriosa embaixada a que o trouxe a Lisboa nesta hora, [...] o Congresso da República saúda o dr. Epitácio Pessoa e se prende ao compromisso de na sua vida parlamentar não esquecer um só momento que o futuro de Portugal e o futuro do Brasil dependem de uma séria aliança econômica entre as duas nações, correspondendo com exatidão, na vida internacional, às afinidades de ordem étnica e sentimental que as unem ${ }^{19}$.

Epitácio Pessoa, por seu turno, aparentemente, retribuiu aos esforços envidados pelos fundadores da Atlantida. Deixou uma mensagem autógrafa, declarando o seu apreço à causa defendida pela revista:

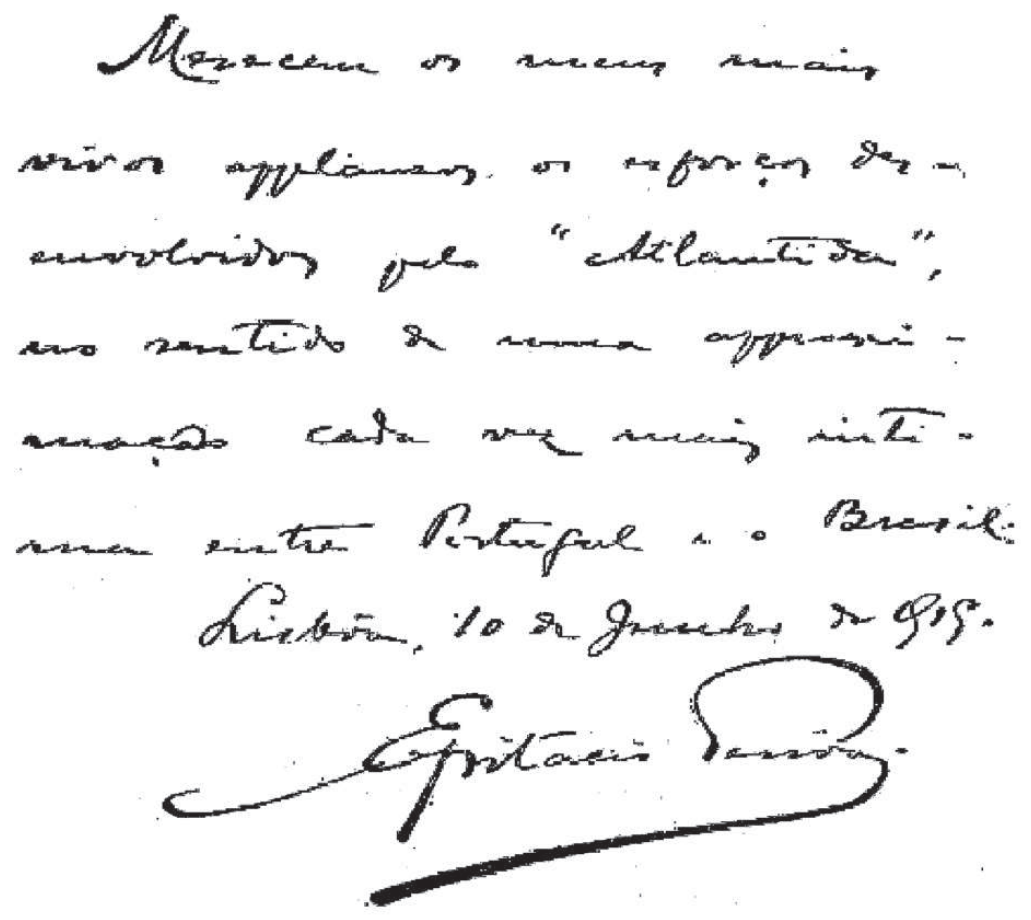

Fonte: Atlantida, $n^{\circ}$ 39. Suplemento, p. I, 1919

Hist.R., Goiânia, v. 16, n. 1, p. 133-149, jan./jun. 2011 
Para além das afinidades intelectuais e da mobilização em torno de políticos e governantes, o periódico buscou outros meios para reforçar a necessidade do estabelecimento de uma comunidade luso-brasileira. Neste sentido, entre outras matérias de natureza econômica, publicou uma análise circunstanciada, acompanhada de tabelas e indicadores financeiros, que apontava as vantagens da união de Brasil e Portugal. O trabalho fora preparado por J. Gaillard, um renomado especialista em questões de navegação internacional e comércio exterior, autor do livro Amérique Latine et Europe ocidentale. L'Amerique face à la guerre (GAILLARD, 1918) ${ }^{20}$.

A demanda parecia bem encaminhada. Logo em seguida, a Atlantida divulgou o projeto de lei do Senador Manoel Gaspar de Lemos, apresentado no parlamento português, em 19 de junho de 1919, propondo o estabelecimento de uma "Grande comissão de estudo para o estreitamento das relações entre Portugal e Brasil", com o objetivo de examinar a seguinte pauta: uniformização da língua e recíproca proteção à propriedade literária; harmonização das instituições de direito privado; mútua elegibilidade dos cidadãos dos dois países para os corpos administrativos, com as justas e indispensáveis restrições; equivalência dos cursos superiores e livre exercício das correspondentes profissões nos dois países; emigração para o Brasil; proteção à navegação comercial dos dois países; estabelecimento de um porto franco em Portugal e quaisquer assuntos que o Poder executivo indique. Como se pode constatar, o senador Gaspar de Lemos havia recuperado os principais pontos do Acordo de Consiglieri Pedroso.

A campanha da Atlantida, finalmente, chegara a um porto seguro. O ente-projeto receberia parecer favorável da Comissão dos Negócios Estrangeiros do Senado. Porém, daí em diante não se tem qualquer notícia da sua tramitação nas fontes portuguesas.

O certo é que apesar da movimentação política e do empenho dos seus dirigentes, a publicação binacional acabaria tragada por um redemoinho de problemas. A periodicidade voltou a sofrer atrasos devido à escassez de recursos e fracassaram as gestões efetuadas junto a Epitácio Pessoa para conseguir apoio financeiro. Como se não bastasse, a atuação de Graça Aranha em Paris deixava a desejar, trazendo sucessivos embaraços aos editores. Além disso, João de Barros afastou-se da direção por razões profissionais. Os dois últimos números da revista já não contariam mais com a sua participação efetiva.

Até sair de circulação, em abril de 1920, a Atlantida veiculou contribuições da nata da intelectualidade que se movimentava no eixo Lisboa - Rio de Janeiro. Testemunhos de uma época, as ideias por eles defendidas mere- 
cem reabilitação. Se por um lado, suas concepções conquistaram muito mais adeptos nos meios letrados do que no âmbito político-institucional, por outro, despertaram memoráveis polêmicas. Sobretudo, no panorama político-cultural brasileiro dos anos 1910-1920, marcado pelo acirramento do nacionalismo intransigente e por campanhas de xenofobia anti-lusitanas, que identificavam aqueles desígnios como manifestações de colonialismo cultural, defendidas por traidores da pátria em conluio com emigrantes portugueses ${ }^{21}$.

Seja como for, o desaparecimento Atlantida não implicou no fim do projeto que seus idealizadores abraçavam. João do Rio faleceria subitamente um ano depois da sua extinção, mas João de Barros e a rede de intelectuais que se formara em torno da revista, sobreviveram-na, continuaram a disseminar suas propostas e influenciaram novas gerações, que voltariam a aventar a conveniência da formação de uma comunidade luso-brasileira.

\section{SWIRLS OF ATLANTIDA (1915-1920)}

ABstRACT: The paper examines the role played by Atlantida review. It was the most significant means for promoting a political-cultural project, focusing to stablish a Luso-Brazilian community. Managed in Rio de Janeiro by Paulo Barreto, the popular João do Rio, and in Lisbon by João de Barros, Atlantida circulated monthly from 1915 to 1920, and constituted an intellectual and sociability space. Alongside the doctrinal reflection about the desirability of closer relations between Brazil and Portugal, the review was engaged in literary issues, historical and contemporary art, which gave it a political and cultural significance at the same time.

Keywoords: Atlantida, cultural review, Luso-Brazilian Community, João de Barros, João do Rio, Luso-Brazilian relations.

\section{NOTAS}

1 Inicialmente, por sugestão de Manoel de Oliveira Pinto, a publicação deveria chamar-se Atlântico, em homenagem ao emblemático oceano singrado pelos navegadores portugueses, em cujas margens se situavam as duas nações.

2 O rompimento fora provocado pela decisão do conde de Paraty de conceder asilo em navios de guerra portugueses aos oficiais da marinha brasileira, que se haviam insurgido contra o governo do marechal Floriano Peixoto, na revolta da Armada. Apesar do restabelecimento das relações oficiais em 1895, mediante gestões da Inglaterra, perdurou durante muito tempo no Brasil um sentimento anti-lusitano, cultivado pelos setores nacionalistas mais acerbados. 
3 “O aparecimento de um grande mensário artístico-literário-social para Portugal e Brasil”. A Rua, Rio de Janeiro, 05 de novembro de 1915, p. 2.

4 “O aparecimento de um grande mensário artístico-literário-social para Portugal e Brasil". A Rua, Rio de Janeiro, 05 de novembro de 1915, p. 2.

5 Acreditamos, tal como evidencia Jean-François Sirinelli, que o Manifesto de lançamento da Atlantida constitui num excelente sismógrafo para examinar a influência e a amplitude das ações dos intelectuais que estiveram à frente do projeto.

6 Cf. Atlantida. Lisboa, nº 1, novembro de 1915.

7 Existem sucessivas notas explicativas da direção da revista, sobre a ausência de colaborações de autores brasileiros previamente anunciadas e que deixaram de ser publicadas, devido aos transtornos provocados pela guerra.

8 Antonio Maria de Bettencourt Rodrigues (1854-1933) doutorou-se em medicina e foi discípulo do famoso Dr Charcot em Paris. Republicano, em 1892, ao ter sido preterido, devido às suas opiniões políticas, no concurso para preenchimento da vaga de director do Manicómio de Lisboa, transferiu-se para o Brasil e se fixou na cidade de São Paulo, onde exerceu a clínica médica e estabeleceu vínculos de amizade com políticos e homens de imprensa. Voltou para Portugal em 1913, assumiu o posto de embaixador na França, cargo do qual seria demitido devido à revolução de 15 de Maio de 1915. Amigo de Sidonio Pais, aderiu ao golpe de Dezembro de 1917, e reinvestido na sua missão em Paris. Com a morte de Sidonio regressou a Portugal, após uma curta permanência na delegação portuguesa à

Conferência de Paz de Paris. Militante unionista, foi ministro dos Negócios Estrangeiros de Portugal, de 9 de Julho de 1926 a 10 de Novembro de 1928.

9 "Uma ideia a defender - A Confederação Luso-Brasileira". Atlantida. Lisboa, no 20, ano III, 1917, p. 659-673.

10 "Uma ideia a defender - A Confederação Luso-Brasileira". Atlantida. Lisboa, no 20, ano III, 1917, p. 659-673.

11 Henrique Lopes de Mendonça (1856-1931) Oficial de Marinha, historiador, poeta e dramaturgo, membro da Academia das Ciências, estudioso dos assuntos coloniais. Por ocasião do Ultimato inglês de 1890, escreveu, com música de Alfredo Keil a marcha A Portuguesa adotada pelo governo republicano, a partir de 1910, como Hino Nacional de Portugal. Em 1923, seria eleito sócio correspondente da Academia Brasileira de Letras.

12 "O inquérito da Atlantida - A Confederação luso-Brasileira”. Atlantida. Lisboa, no 21, ano III, 1917, p.771-773.

13 Álvaro Augusto Manuel Nunes Ribeiro (1878-1933). Oficial de Marinha, apoiou o movimento republicano e depois o Unionista. Grande impulsionador das comunicações na Armada, cumpriu papel pioneiro na implantação do serviço de radiotelegrafia em Portugal. 
14 “A Confederação luso-brasileira - Três opiniões". Atlantida. Lisboa, n 26, ano III, 1917, p. 264-269.

15 “A Confederação luso-brasileira - Três opiniões”. Atlantida. Lisboa, nº 26, ano III, 1917, p. 264-269..

16 João de Barros. "Memórias: a intervenção de João do Rio e também a minha na visita de Epitácio Pessoa a Portugal, em 1919”. MS; sd; s.l.; 10 f. autógrafo. Biblioteca Nacional de Portugal. Seção de Reservados. Cota N 11/5.

17 Atlantida. Lisboa, no 37, ano IV, volume X, 1919, p. 1-4.

18 Lisboa, no 37, ano IV, volume X, 1919, p. 10.

19 Atlantida. Lisboa, no 39, ano IV, volume X, 1919, suplemento, p. IV.

20 "Le développement maritime et l'avenir transatlantique du Brásil". Atlantida, Lisboa, $\mathrm{n}^{\mathrm{o}}$ p. 167-182.

21 Não é demais lembrar que João do Rio tornou-se o principal alvo daqueles movimentos, atacado quase que diariamente pela imprensa, a exemplo da celeuma criada em torno da "questão dos posseiros". O episódio envolveu emigrantes naturais de Povoa do Varzim, os quais não se quiseram naturalizar brasileiros e se repatriaram. Estabelecidos no Rio de Janeiro e especializados na pesca de alto mar, não se misturavam com os brasileiros, nem com seus próprios patrícios de outras localidades. Segundo o escritor Lima Barreto, os "posseiros" formariam uma colônia dentro da própria colônia lusitana no Rio.

\section{REFERÊNCIAS}

ALVES, Jorge Luís dos Santos. Duas interpretações da nacionalidade brasileira. In: XX REUNIÃO DA SOCIEDADE BRASILEIRA DE PESQUISA HISTÓRICA, Anais... Rio de Janeiro, 2005.

ARANHA, J. P. da Graça. Brasil e pangermanismo” In: CHÉRADAME, André. O plano pangermanista desmascarado: a temivel cilada berlineza da "partida nulla". Rio de Janeiro: Livraria Garnier, 1917, p. III-XLII.

BARROS, João de. A aproximação luso-brasileira e a paz. Paris; Lisboa: Livrarias Aillaud; Bertrand, 1919.

CHÉRADAME, André. Le plan pangermaniste démasqueé: Le redoutable piège berlinois de la "partie nulle". Paris: Plon: Nourit et Cie, 1916.

. O plano pangermanista desmascarado: a temivel cilada berlineza da "partida nulla”. Rio de Janeiro: Livraria Garnier, 1917.

GAILLARD, J. Amérique Latine et Europe ocidentale. L’Amerique face à la guerre. Paris: Berger-Levrault, 1918

RIO, João do. Relações Luso-Brasileiras. In: . Portugal d'agora. Lisboa. Porto. 
Notas de viagem. Impressões. Rio de Janeiro: H. Garnier Livreiro, 1911.

RODRIGUES, Antonio Maria Bettencourt. Uma Confederação Luso-Brasileira. Prováveis alianças e grupamentos de nações. Fatos, opiniões e alvitres. Lisboa: Livraria Clássica, 1923.

ROMERO, Silvio. História da Literatura Brasileira. Rio de Janeiro; B. L. Garnier, 1888. O elemento português no Brasil (Conferência). Lisboa: Tipografia da Companhia Nacional, 1902.

SARAIVA, Arnaldo, Modernismo brasileiro e modernismo português. Campinas: UNICAMP, 2004.

SIMÕES, Nuno. Actualidade e permanência do Luso-Brasilismo (Conferências e discursos). Lisboa: Edição do autor, 1960.

SIRINELLI, Jean-François. Intellectuels et passions françaises. Manifestes et pétitions au XX $X^{e}$ siècle. Paris: Gallimard, 1990.

TANNENBERG, Otto Richard . Le rève allemand! La plus grande Allemagne. Loeuvre $d u 20^{\text {eme }}$ siècle. Traduit en français de l'ouvrage Gross-Deutschland, publié en 1911. Lausanne: Payot, 1916. 